\title{
Protective effect of Cassia fistula Linn. on diethylnitrosamine induced hepatocellular damage and oxidative stress in ethanol pretreated rats
}

\author{
KANNAMPALLI PRADEEP, CHANDRASEKARAN VICTOR RAJ MOHAN, \\ KUPANNAN GOBIANAND and SIVANESAN KARTHIKEYAN*
}

\begin{abstract}
Diethylnitrosamine (DEN), found in many commonly consumed foods, is widely reported to induce cancer in animals and humans. The aim of the present study was to investigate the hepatoprotective and antioxidant activities of the leaf extract of the medicinal plant Cassia fistula Linn. against diethylnitrosamine induced liver injury in ethanol pretreated rats. Albino Wistar rats, pretreated with ethanol for 15 days, were administered a single dose of DEN. Thirty days after DEN administration, hepatotocellular damage was observed histologically, along with elevated levels of serum AST, ALT, ALP, LDH, $\gamma$-GT and bilirubin and a simultaneous fall in the levels of the marker enzymes in the liver tissue. Liver oxidative stress was confirmed by elevated levels of lipid peroxidation (LPO) and a decrease in enzymic and non-enzymic antioxidants activities. Oral administration of the ethanolic leaf extract (ELE) of Cassia fistula for 30 days to ethanol + DEN treated rats significantly improved the above alterations in the markers of hepatotoxicity and oxidative stress, resulting in the reversal of most of the parameters studied and were comparable to the standard hepatoprotective drug silymarin.
\end{abstract}

Key terms: antioxidants; Cassia fistula; diethylnitrosamine; hepatoprotective; lipid peroxidation; silymarin .

\section{INTRODUCTION}

Nitrosamines are compounds formed by the combination of amines and nitrates or nitrites. Studies have shown that nitrosamines can be formed in the gastric juice of the human stomach by a process commonly referred to as endogenous nitrosation. The bacteria in the mouth chemically reduce nitrate found in many vegetables to nitrite, which in turn can form nitrosating agents. Many foods that contain amines can react with these nitrosating agents in the acidic environment of the stomach to form nitrosamines (Jakszyn and Gonzalez, 2006). Diethylnitrosamine (DEN), a representative compound of the nitrosamine family, is a well-known hepatocarcinogen, forming DNAcarcinogen adducts in the liver and inducing hepatocellular carcinomas without cirrhosis through the development of putative preneoplastic enzyme-altered hepatocellular focal lesions (Singer and Crunderger, 1984). DEN is widely reported to be found in the environment, in tobacco smoke and is also synthesized endogenously (Sander, 1967; Tricker and Preussmann, 1991). The presence of DEN in wide varieties of foods, such as cheese, soybean, smoked, salted and dried fish, cured meat, alcoholic beverages, and ground water having high level of nitrates makes the human population vulnerable to its exposure (IARC, 1972). DEN induces oxidative stress possibly due to the generation of reactive oxygen species (ROS), which are capable of initiating peroxidative damage to the cell (Bansal et al., 2005). DEN is biotransformed by mixed-function cytochrome P-450 dependent monooxidase systems and its metabolic activation is reported to be responsible for the onset of the toxic effects

\footnotetext{
* Corresponding author: Dr. S. Karthikeyan, Senior Lecturer, Department of Pharmacology and Environmental Toxicology, Dr. A.L.M. P.G. Institute of Basic Medical Science, University of Madras, Taramani, Chennai 600113. India. Phone: 91044-2454-5317, Fax: 91-044-2454-0709, E. Mail: kannampallipradeep@gmail.com
} 
(Zimmerman, 1993). Intermediate reactive compounds originating from the bioactivation of DEN are known to form covalent bonds with important cell constituents, thus inducing the onset of mutations, cancer, and necrosis (Schmitt et al., 1993). Microsomal activation of DEN involves cytochrome P450 2E1 and hence compounds that selectively activate cytochrome P450 systems are being widely used by several investigators to induce hepatocellular carcinoma in experimental animals. Ethanol is a well known hepatotoxicant and induction of cytochrome $\mathrm{P} 4502 \mathrm{E} 1$ is believed to be the central pathway by which ethanol generates a state of oxidative stress thereby causing hepatotoxicity (Kim et al., 2006). Studies have shown that ethanol strengthens the toxicity of DEN by augmenting cytochrome P450 2E1 mediated metabolism of DEN (Yang et al., 1990). As ethanol consumption has become increasingly common among the human population, and with DEN being detected in a wide variety of commonly consumed food products, the risk of DEN induced hepatotoxicity and hepatocellular carcinoma increases several folds. This underscores the need for development of novel compounds with potent hepatoprotective and antioxidant activity so as to prevent or treat DEN induced cellular damage. Studies have suggested that dietary intake of phytochemicals could be a useful strategy to prevent the deleterious effects of carcinogens and mutagens (Spron and Suh, 2000), as plant based compounds are easily available, can be synthesized in large quantities and can be administered without any deleterious side effects.

Cassia fistula Linn. (Indian Labernum or Golden shower), native to the Indian subcontinent, has long been used in traditional Indian medicine for the treatment of various ailments (Chatterjee and Pakrashi, 1992). Cassia fistula (Family: Leguminosae), is widely used for its antitumor (Gupta et al., 2000), hepatoprotective (Bhakta et al., 1999; 2000), antifertility (Yadav and Jain, 1999), and antioxidant (Luximon-Ramma et al., 2002; Siddhuraju et al., 2002) properties, as well as its actions on the central nervous systems (Mazumdar et al., 1998), wound healing (Senthilkumar et al., 2006), and inhibitory effect on leukotriene biosynthesis (Sunilkumar and Muller, 1998). The present investigation was designed to evaluate the hepatoprotective and antioxidant properties of the ethanolic leaf extract of Cassia fistula against hepatotoxicity induced by diethylnitrosamine in ethanol pretreated albino Wistar rats.

\section{MATERIALS AND METHODS}

\section{Animals}

Adult male albino Wistar rats $(180 \pm 10 \mathrm{~g})$, procured from Tamil Nadu Veterinary and Animal Sciences University (TANUVAS), were used for the study. The animals were housed in polypropylene cages $(n=3 /$ cage $)$ at room temperature $\left(25-28{ }^{\circ} \mathrm{C}\right)$ and maintained under $12 \mathrm{~h}$ light/dark cycle. The rats were fed pellet diet and water ad libitum. The animals were acclimatized to laboratory conditions for about seven days before commencement of the experiments. The study was performed after obtaining necessary clearance from the Institutional Animal Ethical Committee (IAEC) of CPCSEA (Committee for the Purpose of Control and Supervision of Experiments on Animals).

\section{Chemicals}

Diethylnitrosamine (DEN) and 1,1,3,3, tetraethoxypropane were purchased from M/s. Sigma Chemical Company, USA. 55 'dithiobis-2-nitrobenzoic acid (DTNB) and 1-chloro 2, 4-dinitrobenzene (CDNB) were purchased from SISCO Research Laboratories, Chennai, India. Silymarin was obtained as gratis from Central Drug Research Institute (CDRI), Lucknow, India. All other chemicals used were of analytical grade and purchased locally.

\section{Plant material}

Fresh leaves of Cassia fistula, collected from the Tamil Nadu Medicinal Plant Farms and Herbal Medicine Corporation 
Ltd (TAMPCOL), Chennai, India, during the month of July-August, were authenticated by the Chief Botanist of TAMPCOL. A herbarium specimen of the leaf was also deposited in the Botanical Survey of India, Coimbatore and another in Presidency College, Chennai.

\section{Preparation of the ethanolic leaf extract (ELE)}

The freshly collected leaves were first washed with tap water to remove external dirt and then rinsed with distilled water. The leaves were then shade dried for about $72 \mathrm{~h}$ and crushed into a coarse powder using a blender. One hundred gram of the coarse powder was kept soaked in ethanol (1L, 95\%) for 30 days with occasional shaking. After 30 days, the ethanolic leaf extract (ELE) was filtered using Whatman filter paper no. 1 and concentrated under reduced pressure. The final yield of ELE was $19 \%(\mathrm{w} / \mathrm{w})$, which was stored at $4^{\circ} \mathrm{C}$ until use. Quantitative phytochemical analysis of the extract was performed as described by Harborne (1978).

\section{Experimental Design}

Rats were randomly divided into 8 groups with 6 animals in each group. The experimental design and treatment protocol were as follows:

Group I Rats served as normal control and were orally administered saline for 45 days.

Group II Rats were treated with ethanol (4 g/kg b.w., p.o.) for 15 days (Bautista and Spitzer, 1999) and were then administered saline until day 45 .

Group III Rats were treated with saline for 15 days followed by administration of a single dose of DEN (100 mg/kg b.w., i.p.) on day 16 (Goldsworthy et al., 1986). Animals were then administered saline until day 45.

Group IV Rats were pretreated with ethanol (4 g/kg b.w., p.o.) for
15 days followed by administration of a single dose of DEN (100 mg/kg b.w., i.p.) on day 16. Animals were then administered saline until day 45.

Group V Rats were pretreated with ethanol (4 g/kg b.w., p.o.) for 15 days followed by administration of a single dose of DEN (100 mg/kg b.w., i.p.) on day 16 . ELE $(500 \mathrm{mg} / \mathrm{kg}$ b.w., p.o.) was administered from 1 to 45 days.

Group VI Rats were pretreated with ethanol (4 $\mathrm{g} / \mathrm{kg}$ b.w., p.o.) for 15 days followed by a single dose of DEN (100 mg/kg b.w., i.p.) on day 16. Silymarin (50 $\mathrm{mg} / \mathrm{kg}$ b.w., p.o.) was administered from 1 to 45 days.

Group VII Rats were administered ELE (500 mg/kg b.w., p.o.) alone for 45 days.

Group VIII Rats were administered silymarin (50 mg/kg b.w., p.o.) alone for 45 days.

The dose of ELE was selected by performing an effective dose fixation study as part of a preliminary investigation and also based on previously published reports. Acute ( 7 days) and sub-chronic toxicity (30 days) of ELE were also performed to evaluate the safety of the extract. It was found to be safe and non-toxic as it did not cause toxicity and mortality, even for the highest dose $(2500 \mathrm{mg} / \mathrm{kg})$ tested. Silymarin at a dose of $50 \mathrm{mg} / \mathrm{kg}$ was used as a standard reference drug (Fraschini et al., 2002).

At the end of the experimental period (45 days), animals were subjected to mild ether anesthesia and blood was collected from the retro orbital plexus for serum separation (3000 rpm for $15 \mathrm{~min}$ at $4^{\circ} \mathrm{C}$ ). Animals were then sacrificed by decapitation and the livers were excised, washed in ice cold saline and blotted to dryness. A $10 \%$ homogenate of the liver tissue was prepared in Tris-HCl buffer (0.1M; pH 7.4), centrifuged (1000 rpm for 10 min at $4^{\circ} \mathrm{C}$ ) to pellet the cell debris and 
the clear supernatant used for biochemical assays. A piece of the liver tissue was also fixed in $10 \%$ neutral buffered formalin and stained with hematoxylin-eosin for histopathological analysis.

\section{Biochemical analysis}

Aspartate and alanine transaminases (AST and ALT) were assayed in the serum and liver tissue homogenate according to the method of Bergmeyer et al (1978). Alkaline phosphatase (ALP) was assayed in the serum and liver tissue homogenate according to King (1965a) using disodium phenyl phosphate as substrate. Lactate dehydrogenase (LDH) was assayed by the method of King (1965b) using lithium lactate as substrate. $\gamma$-Glutamyl transferase $(\gamma-\mathrm{GT})$ in serum and liver was estimated as described by Rosalki and Rau (1972). Total serum bilirubin was estimated using a commercial kit for bilirubin estimation. Protein content was estimated by the method of Bradford (1976) using bovine serum albumin as the standard. The hepatic lipid peroxidation (LPO) level was determined as described by Ohkawa et al (1979). The activity of hepatic superoxide dismutase (SOD) was assayed according to the method of Marklund and Marklund (1974) and catalase (CAT) was assayed by the method of Sinha (1972). Hepatic glutathione $(\mathrm{GSH})$ content was estimated by the method described by Beutler et al (1953). The activity of glutathione-stransferase (GST) in the liver tissue was estimated by the method of Habig et al (1974). The activity of glutathione peroxidase (GPx) in the liver was estimated by the methods of Rotruck et al (1973). The activity of hepatic glutathione reductase (GR) was estimated in the liver tissue by the method of Mize and Langdon (1962). The vitamin-C content in the liver was estimated by the procedure of Omaye et al (1979) and vitamin-E was estimated as described by Varley et al (1976). The activity of $\mathrm{Na}^{+} / \mathrm{K}^{+}$ATPase in the liver tissue was estimated by Bonting (1970), $\mathrm{Ca}^{2+}$ ATPase as described by Hjerten and Pan (1983) and $\mathrm{Mg}^{2+}$ ATPase by the method of Ohnishi et al (1982), in which the liberated phosphate was estimated spectrophotometrically.

\section{Statistical analysis}

The data obtained were subjected to one way analysis of variance (ANOVA) and a post hoc test was performed for inter-group comparisons using Tukey's multiple comparison with the SPSS software package (Version 7.5) for Windows. Values are expressed as mean \pm standard deviation (S.D) for 6 animals in each group. P values $<0.05$ were considered significant. The percentage of hepatoprotection offered by ELE and silymarin was calculated as described by Rajesh and Latha, (2004).

\section{RESULTS}

Effect of ELE treatment on serum transaminases and alkaline phosphatase

Data on the status of marker enzymes of hepatotoxicity in serum of control and experimental animals is presented in Table 1. Ethanol alone treatment (Group II) caused a significant increase in AST, ALT and ALP in the serum as compared to normal control (Group I). DEN alone treatment (Group III) also produced a highly significant increase in all the above parameters in serum. In ethanol + DEN treated rats (Group IV), a significant 2 fold increase in AST, 3 fold increase in ALP and 4 fold increase in ALT were observed in serum as compared to normal control. Treatment of ELE for 45 days to ethanol + DEN treated rats (Group V) significantly prevented the increase in the activities of AST, ALT and ALP. Similarly, treatment with silymarin to ethanol + DEN treated rats (Group VI) also produced an identical hepatoprotective effect comparable to post treatment with ELE.

Effect of ELE treatment on serum $L D H$, $\gamma G T$, and bilirubin

Data presented in Table 2 shows that ethanol alone treatment caused a highly significant increase in serum bilirubin, 
LDH, and $\gamma$-GT (2 fold) activity in serum. A similar trend was also observed in rats treated with DEN alone. In rats treated with ethanol + DEN, more than 2 fold increase in LDH, $\gamma$-GT activities and serum bilirubin (4 fold) was observed, indicating an augmented hepatotoxic effect in this combined treatment. This augmentation in the status of LDH, $\gamma-\mathrm{GT}$, and total bilirubin induced by ethanol + DEN treatment was significantly decreased in rats that were treated with ELE as well as silymarin.

TABLE I

Effect of ELE on the status of marker enzymes of hepatotoxicity in the serum of control and experimental animals

\begin{tabular}{lccc}
\hline TreatmentGroups & AST (IU/L) & ALT (IU/L) & ALP (IU/L) \\
\hline Group I & $37.05 \pm 0.80$ & $41.58 \pm 1.71$ & $105.93 \pm 2.11$ \\
Group II & $45.07 \pm 2.53^{\mathrm{a}}$ & $75.65 \pm 2.17^{\mathrm{a}}$ & $146.16 \pm 8.13^{\mathrm{a}}$ \\
Group III & $64.26 \pm 1.13^{\mathrm{a}}$ & $82.37 \pm 1.88^{\mathrm{a}}$ & $180.45 \pm 2.32^{\mathrm{a}}$ \\
Group IV & $84.01 \pm 2.57^{\mathrm{a}}$ & $183.23 \pm 6.64^{\mathrm{a}}$ & $375.81^{\text {“ }} \pm 16.51^{\mathrm{a}}$ \\
Group V & $47.26 \pm 3.96^{\mathrm{a}, \mathrm{b}, \mathrm{c}}$ & $80.50 \pm 3.83^{\mathrm{a}, \mathrm{b}, \mathrm{c}}$ & $208.13 \pm 16.79^{\mathrm{a}, \mathrm{b}, \mathrm{c}}$ \\
Group VI & $46.06 \pm 3.00^{\mathrm{d}}$ & $80.68 \pm 4.34^{\mathrm{d}}$ & $198.20 \pm 22.48^{\mathrm{d}}$ \\
Group VII & $38.26 \pm 1.53^{\mathrm{d}}$ & $42.66 \pm 4.13^{\mathrm{d}}$ & $103.66 \pm 5.83^{\mathrm{d}}$ \\
Group VIII & $37.85 \pm 1.26$ & $44.65 \pm 4.51$ & $109.15 \pm 7.04$ \\
& \multicolumn{4}{c}{62.13} \\
ELE & 78.25 & $\%$ of Hepatoprotection \\
Silymarin & 80.81 & 72.52 & 65.81 \\
\hline
\end{tabular}

Values expressed as mean \pm S.D of 6 animals in each group. Comparisons were made as a - compared to Group I; b - compared to Group II; c - compared to Group III; d - compared to Group IV. P $<0.001$ was considered significant.

TABLE II

Effect of ELE on the status of marker enzymes of hepatotoxicity in the serum of control and experimental animals

\begin{tabular}{|c|c|c|c|}
\hline TreatmentGroups & LDH (IU/L) & $\gamma-\mathrm{GT}(\mathrm{IU} / \mathrm{L})$ & Bilirubin $(\mathrm{mg} / \mathrm{dL})$ \\
\hline Group I & $149.07 \pm 2.94$ & $90.36 \pm 1.71$ & $0.460 \pm 0.022$ \\
\hline Group II & $278.39 \pm 4.97^{\mathrm{a}}$ & $188.66 \pm 5.19^{\mathrm{a}}$ & $0.860 \pm 0.022^{\mathrm{a}}$ \\
\hline Group III & $287.36 \pm 2.17^{\mathrm{a}}$ & $186.02 \pm 1.62^{\mathrm{a}}$ & $1.516 \pm 0.093^{\mathrm{a}}$ \\
\hline Group IV & $389.03 \pm 8.16^{\mathrm{a}, \mathrm{b}, \mathrm{c}}$ & $223.47 \pm 1.43^{\mathrm{a}, \mathrm{b}, \mathrm{c}}$ & $2.104 \pm 0.071^{\mathrm{a}, \mathrm{b}, \mathrm{c}}$ \\
\hline Group V & $220.34 \pm 8.39^{\mathrm{d}}$ & $106.15 \pm 1.21^{\mathrm{d}}$ & $0.611 \pm 0.100^{\mathrm{d}}$ \\
\hline Group VI & $217.47 \pm 4.83^{\mathrm{d}}$ & $98.46 \pm 9.52^{\mathrm{d}}$ & $0.576 \pm 0.057^{\mathrm{d}}$ \\
\hline Group VII & $151.18 \pm 2.59$ & $90.11 \pm 4.74$ & $0.520 \pm 0.06$ \\
\hline \multirow[t]{2}{*}{ Group VIII } & $147.29 \pm 3.49$ & $90.28 \pm 5.21$ & $0.509 \pm 0.05$ \\
\hline & \multicolumn{3}{|c|}{$\%$ of Hepatoprotection } \\
\hline ELE & 70.29 & 88.13 & 90.81 \\
\hline Silymarin & 71.49 & 93.91 & 92.94 \\
\hline
\end{tabular}

Values expressed as mean \pm S.D of 6 animals in each group. Comparisons were made as a - compared to Group I; b - compared to Group II; c - compared to Group III; d - compared to Group IV. P $<0.001$ was considered significant. 
Effect of ELE treatment on the status of LPO and activities of SOD and CAT in the liver tissue

Lipid peroxidation (LPO) in the liver tissue was slightly elevated in ethanol alone treated rats (Table 3). However, DEN alone treatment, as well as ethanol + DEN treatment, caused a significant 2 fold and 3 fold increase respectively in the status of LPO in the liver tissue of rats. Ethanol and DEN treatment produced an approximate 30 - $35 \%$ decrease in the activities of SOD and CAT in the liver tissue of rats, which was found to be more than their individual treatments. Treatment of ELE completely prevented the 3 fold increase in LPO induced by ethanol + DEN in the liver tissue of rats. Further, this treatment also caused a reversal in the pronounced decrease in the activities of SOD and CAT.

Effect of ELE treatment on hepatic GSH levels and on the activities of GST, GPX and $G R$ in the liver tissue

The status of GSH and the activities of GST, GPx and GR in the liver tissue of control and experimental animals is presented in Table 4. Aa almost 50\% decrease in the status of GSH, GST, GPx and GR were noticed in rats treated with ethanol + DEN, which was found to be more than their individual treatments. Administration of ELE significantly protected the liver against fall in the levels of GSH, GST and GR induced by ethanol + DEN treatment and the protection offered by ELE was comparable to that of silymarin

Effect of ELE treatment on the status of vitamin-C and vitamin-E in the liver tissue

Ethanol + DEN treatment caused a more pronounced decrease (approximately 40 $50 \%$ ) in the status of vitamin $\mathrm{C}$ and vitamin $\mathrm{E}$ in the liver tissue of rats as compared to control animals (Fig $1 \& 2$ ). Individual treatments of ethanol and DEN also produced a significant fall in the status of these parameters as compared to normal control, although the decrease in the level was less when compared to combined treatment. Oral administration of ELE was found to offer significant protection to liver tissue against decrease in the status of vitamin $\mathrm{C}$ and vitamin $\mathrm{E}$ induced by ethanol + DEN treatment.

\section{TABLE III}

Effect of ELE on the levels of hepatic lipid peroxidation and activity of SOD and Catalase in the liver tissue of control and experimental animals

\begin{tabular}{lccc}
\hline TreatmentGroups & LPO & SOD & Catalase \\
\hline Group I & $0.094 \pm 0.004$ & $1.416 \pm 0.127$ & $5.07 \pm 0.09$ \\
Group II & $0.120 \pm 0.001^{\mathrm{a}}$ & $0.669 \pm 0.02^{\mathrm{a}}$ & $3.46 \pm 0.09^{\mathrm{a}}$ \\
Group III & $0.218 \pm 0.003^{\mathrm{a}}$ & $0.737 \pm 0.016^{\mathrm{a}}$ & $2.88 \pm 0.04^{\mathrm{a}}$ \\
Group IV & $0.354 \pm 0.015^{\mathrm{a}, \mathrm{b}, \mathrm{c}}$ & $0.481 \pm 0.022^{\mathrm{a}, \mathrm{b}, \mathrm{c}}$ & $1.82 \pm 0.11^{\mathrm{a}, \mathrm{b}, \mathrm{c}}$ \\
Group V & $0.104 \pm 0.003^{\mathrm{d}}$ & $1.286 \pm 0.024^{\mathrm{d}}$ & $4.12 \pm 0.44^{\mathrm{d}}$ \\
Group VI & $0.109 \pm 0.006^{\mathrm{d}}$ & $1.391 \pm 0.019^{\mathrm{d}}$ & $4.81 \pm 0.19^{\mathrm{d}}$ \\
Group VI & $0.095 \pm 0.013$ & $1.422 \pm 0.006$ & $4.95 \pm 0.06$ \\
Group VIII & $0.092 \pm 0.013$ & $1.419 \pm 0.009$ & $4.93 \pm 0.19$ \\
\cline { 2 - 4 } & & $\%$ of Protection \\
\cline { 2 - 4 } ELE & 96.15 & 86.10 & 70.80 \\
Silymarin & 94.23 & 97.40 & 92.00 \\
\hline
\end{tabular}

Values expressed as mean \pm S.D of 6 animals in each group. Comparisons were made as a - compared to Group I; b - compared to Group II; c - compared to Group III; d - compared to Group IV. P $<0.001$ was considered significant. 
TABLE IV

Effect of ELE on the levels of hepatic GSH and activity of GSH dependent enzymes in the liver tissue of control and experimental animals

\begin{tabular}{lcccc}
\hline TreatmentGroups & GSH & GST & GPx & GR \\
\hline Group I & $20.36 \pm 0.11$ & $20.06 \pm 0.49$ & $2.22 \pm 0.12$ & $0.057 \pm 0.002$ \\
Group II & $14.28 \pm 0.07^{\mathrm{a}}$ & $19.08 \pm 0.29^{\mathrm{a}}$ & $1.85 \pm 0.05^{\mathrm{a}}$ & $0.034 \pm 0.004^{\mathrm{a}}$ \\
Group III & $16.66 \pm 0.11^{\mathrm{a}}$ & $14.90 \pm 0.12^{\mathrm{a}}$ & $1.19 \pm 0.02^{\mathrm{a}}$ & $0.039 \pm 0.005^{\mathrm{a}}$ \\
Group IV & $12.71 \pm 0.42^{\mathrm{a}, \mathrm{b}, \mathrm{c}}$ & $9.60 \pm 0.32^{\mathrm{a}, \mathrm{b}, \mathrm{c}}$ & $0.81 \pm 0.06^{\mathrm{a}, \mathrm{b}, \mathrm{c}}$ & $0.023 \pm 0.008^{\mathrm{a}, \mathrm{b}, \mathrm{c}}$ \\
Group V & $18.82 \pm 0.21^{\mathrm{d}}$ & $16.04 \pm 0.35^{\mathrm{d}}$ & $1.89 \pm 0.05^{\mathrm{d}}$ & $0.046 \pm 0.003^{\mathrm{d}}$ \\
Group VI & $18.79 \pm 0.21^{\mathrm{d}}$ & $16.28 \pm 0.38^{\mathrm{d}}$ & $1.94 \pm 0.05^{\mathrm{d}}$ & $0.050 \pm 0.004^{\mathrm{d}}$ \\
Group VII & $19.33 \pm 0.19$ & $19.43 \pm 0.31$ & $2.07 \pm 0.04$ & $0.050 \pm 0.002$ \\
Group VIII & $19.94 \pm 0.17$ & $19.65 \pm 0.36$ & $2.13 \pm 0.06$ & $0.056 \pm 0.002$ \\
\cline { 2 - 5 } & 79.90 & \multicolumn{2}{c}{$\%$} \\
ELE & 79.47 & 61.56 & 76.59 & 68.57 \\
Silymarin & \multicolumn{5}{c}{63.86} & 80.14 & 69.56 \\
\hline
\end{tabular}

Values expressed as mean \pm S.D of 6 animals in each group. Comparisons were made as a - compared to Group I; b - compared to Group II; c - compared to Group III; d - compared to Group IV. P < 0.001 was considered significant.

Effect of ELE treatment on the status of membrane bound ATPases in the liver tissue

Ethanol and DEN treatment caused a 50 $60 \%$ reduction in the activities of $\mathrm{Na}^{+} / \mathrm{K}^{+}$ ATPase, $\mathrm{Ca}^{2+}$ ATPase and $\mathrm{Mg}^{2+}$ ATPase in the liver tissue of rats as compared to control (Table 5). Ethanol alone treatment and DEN alone treatment also produced a significant fall in the activity of these membrane bound ATPase in the liver tissue as compared to control, but was not as pronounced as the case of ethanol and DEN treatments. Treatment of ethanol and DEN administered rats with ELE significantly prevented the reduction in the activities of all the membrane bound ATPases and reverted their levels towards normalcy.

\section{Histological examination of the liver tissue}

Histopathology of the liver tissue of control and experimental rats are presented in Fig 3. The liver sections of rats treated with ethanol alone (Group II) showed swollen hepatocytes, containing occasional micro vesicles when observed under the microscope, indicating mild hepatocellular damage characteristic to ethanol toxicity. Liver sections of rats treated with DEN alone (Group III) showed mild dilation of sinusoidal space and granules in the cytoplasm of hepatocytes, indicating hepatocellular damage. Enlarged and dysplastic hepatocytes with increased sinusoidal space were observed in the liver sections of rats treated with ethanol and DEN (Group IV). They also showed cytoplasm with coarse granules, and dysplastic and the premalignant state of hepatocytes were observed, which is a clear indication of more pronounced hepatocellular damage, observed during their combined treatment. Treatment with ELE after ethanol and DEN administration (Group V) showed a reduction in the sinusoidal spaces and absence of granules in the cytoplasm. Further, dysplastic and premalignant state of hepatocytes were not observed in this group and it showed a pattern of recovery similar to that of silymarin treated animals. Treatment with ELE alone (Group VI) and silymarin alone (Group VII) did not cause any pathological changes in the liver tissue of rats and were comparable with that of saline treated normal control (Group I). 


\section{DISCUSSION}

DEN, an important carcinogen found in human environment, is reported to produce oxidative stress through the generation of ROS and alter the antioxidant defense system in tissues (Mittal et al., 2006). The present study documents the hepatoprotective and antioxidant activity of the ethanolic leaf extract (ELE) of the traditional Indian medicinal plant Cassia fistula Linn. against liver injury induced by DEN in ethanol pretreated rats. Studies have shown ethanol to be a potent inducer of cytochrome P-450 enzymes (Kim et al., 2006), which plays a major role in the metabolism of DEN resulting in the release of highly reactive intermediates leading to hepatotocellular damage. In the present investigation, pretreatment with ethanol before DEN administration resulted in a profound alterations in most of the parameters investigated when compared to their individual treatments. Since ethanol is an inducer of cytochrome P-450 enzymes, administration of ethanol might have caused the induction of cytochrome P-450 enzyme systems, resulting in faster metabolism of DEN, ultimately releasing high amounts of toxic intermediates or ROS. This fact is substantiated by the highly pronounced alterations in the parameters investigated in DEN administered rats that were pretreated with ethanol compared to rats treated with DEN alone.

Cellular damage exhibits good correlation with the enzyme leakage (Sherawat and Sultana, 2006). Serum AST, ALT, ALP, $\gamma$-GT and bilirubin are the most sensitive markers employed in the diagnosis of hepatic damage (Sallie et al., 1991). The increase in the activities of these enzymes in serum and subsequent fall in the tissue (data not shown) might be due to the leakage of these cytosolic enzymes into the in circulatory system resulting from hepatocellular damage during ethanol and DEN administration. This is indicative of the onset of hepatocellular damage due to

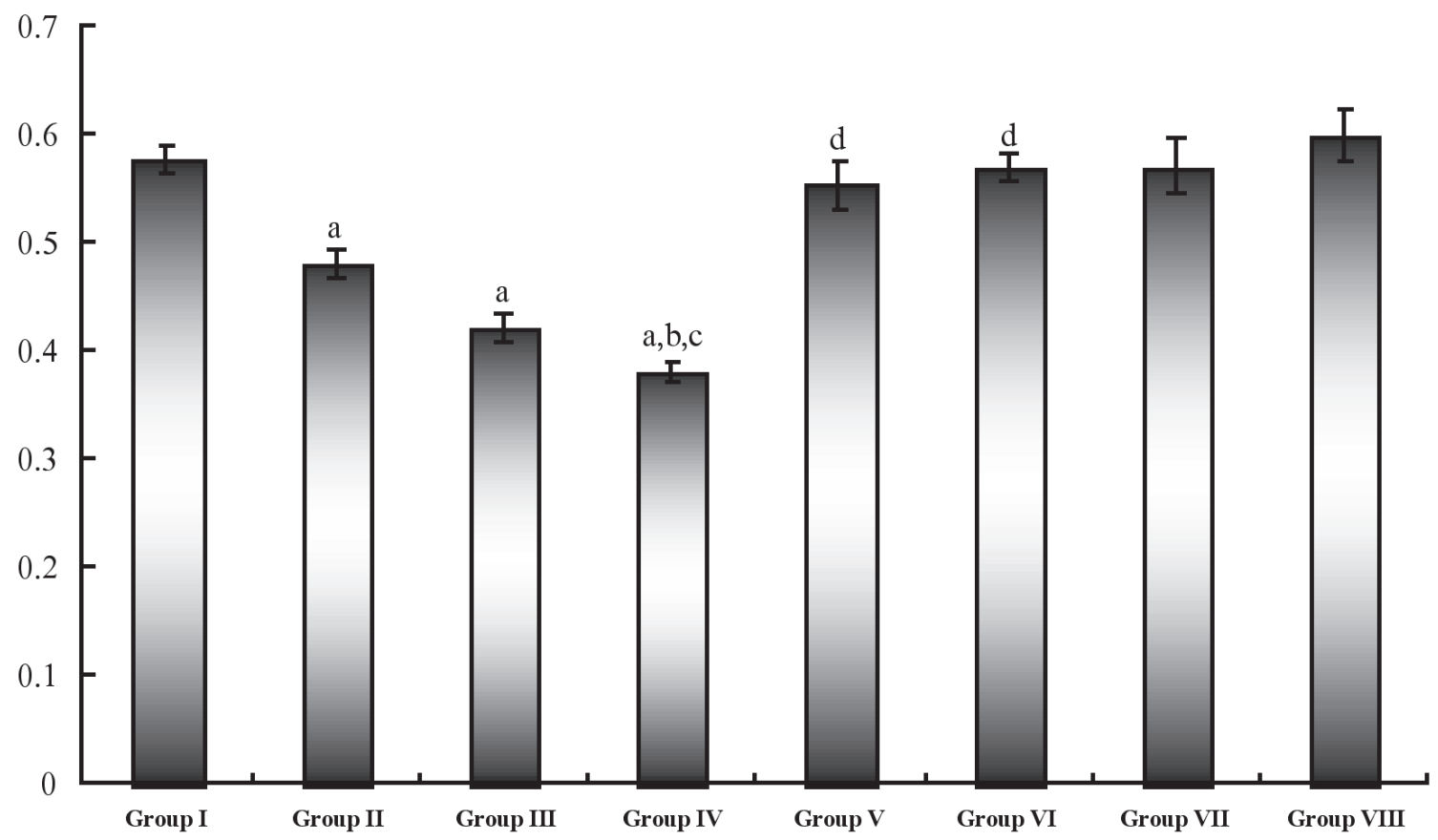

Figure 1: Effect of ELE treatment on the status of vitamin $C$ in the liver tissue of control and experimental animals

Values expressed as mean \pm S.D of 6 animals in each group. Comparisons were made as a compared with Group I; b - compared with Group II; c - compared with Group III; d - compared with Group IV. P $<0.001$ was considered significant. 
liver dysfunction and disturbance of the biosynthesis of these enzymes, with alteration in the permeability of liver membrane. Treatment with ELE significantly reversed the alterations in the status of these markers to normal levels, possibly by maintaining the hepatocellular membrane integrity. This is an indicator of possible hepatoprotective property offered by ELE.

The status of lipid peroxidation (LPO) has been extensively used as a marker of oxidative stress because membrane lipids are more susceptible to ROS (Sayeed et al., 2003). Oxidative damage to cells or tissues occurs when the concentration of ROS generated exceeds the antioxidant capability of the cell (Sies, 1985). In the present investigation, the 3 fold increase in the levels of LPO and highly pronounced decreased levels of SOD, CAT and GPX observed during ethanol and DEN administration is indicative of oxidative stress resulting from the reactive metabolites of DEN. Further, the observed decreases in the levels of non-enzymatic antioxidant (vitamin C, vitamin $\mathrm{E}$ and GSH) and enzymatic antioxidants (SOD, CAT and GPx) during ethanol and DEN administration indicate the complete disruption of the antioxidant defense mechanism of the liver. The decline in these enzyme activities could also be due to a reduction in their biosynthesis or their excessive utilization in trapping the free radicals generated. Administration of ELE significantly reduced LPO and also improved the status of enzymic and nonenzymic antioxidants in the liver tissue. In the absence of endogenous cellular antioxidants, the phytochemicals present in ELE supplemented as exogenous antioxidants by scavenging ROS, thus preventing further peroxidative damage to the hepatocytes. This is attributed to the recovery in the levels of LPO and also in the status of enzymic and non-enzymic antioxidants during ELE treatment.

A significant decrease in the activities of GSH dependent enzymes, GST and GR, was observed in DEN treated rats, which may be due to the decreased expression of these antioxidants during hepatocellular damage. The decreased hepatic GSH in ethanol and DEN intoxicated rats could be the result of hexose monophosphate (HMP) shunt impairment and thereby reduced NADPH availability, which in turn decreases the ability to recycle GSSG to GSH (Lu, 1999). The activities of some intracellular antioxidant enzymes have been reported to decrease with the increase in lipid peroxidation levels (Diplock et al., 1994) and this fact is concomitant with the results of this study. It was also reported that severe damage to the liver decreases antioxidant defenses in the liver (Seven et al., 2004). It is likely that post treatment of

TABLE V

Effect of ELE on activity of membrane bound ATPases the liver tissue of control and experimental animals

\begin{tabular}{lccc}
\hline TreatmentGroups & $\mathrm{Na}^{+} / \mathrm{K}^{+} \mathrm{ATPase}$ & $\mathrm{Ca}^{2+}$ ATPase & $\mathrm{Mg}^{2+} \mathrm{ATPase}$ \\
\hline Group I & $0.181 \pm 0.004$ & $0.210 \pm 0.003$ & $0.413 \pm 0.003$ \\
Group II & $0.151 \pm 0.002^{\mathrm{a}}$ & $0.168 \pm 0.003^{\mathrm{a}}$ & $0.308 \pm 0.008^{\mathrm{a}}$ \\
Group III & $0.175 \pm 0.003^{\mathrm{a}}$ & $0.190 \pm 0.004^{\mathrm{a}}$ & $0.363 \pm 0.005^{\mathrm{a}}$ \\
Group IV & $0.097 \pm 0.004^{\mathrm{a}, \mathrm{b}, \mathrm{c}}$ & $0.091 \pm 0.007^{\mathrm{a}, \mathrm{b}, \mathrm{c}}$ & $0.156 \pm 0.010^{\mathrm{a}, \mathrm{b}, \mathrm{c}}$ \\
Group V & $0.161 \pm 0.009^{\mathrm{d}}$ & $0.171 \pm 0.007^{\mathrm{d}}$ & $0.363 \pm 0.008^{\mathrm{d}}$ \\
Group VI & $0.174 \pm 0.011^{\mathrm{d}}$ & $0.175 \pm 0.002^{\mathrm{d}}$ & $0.358 \pm 0.011^{\mathrm{d}}$ \\
Group VII & $0.179 \pm 0.002$ & $0.198 \pm 0.008$ & $0.369 \pm 0.014$ \\
Group VIII & $0.187 \pm 0.01$ & $0.204 \pm 0.012$ & $0.395 \pm 0.005$ \\
\hline
\end{tabular}

Values expressed as mean \pm S.D of 6 animals in each group. Comparisons were made as a - compared to Group I; b - compared to Group II; c - compared to Group III; d - compared to Group IV. P $<0.001$ was considered significant. 
ELE maintains the activity of GR and GST in the liver by inhibiting LPO and maintaining GSH levels, which is indicative of the potent antioxidant activity possessed by ELE. The hepatoprotective effects of ELE may also be due to its ability to enhance glutathione production by providing more substrate for reactive intermediates that promote detoxification mechanisms. This also might be the reason for the restoration of other antioxidant enzymes such as SOD, CAT and GPx.

The combined administration of ethanol followed by DEN treatment also decreased the activities of different membrane bound ATPases to a significant extent, which is an indication of hepatocellular membrane damage. These membrane bound enzymes are responsible for the transport of respective ions across the cell membrane at the expense of ATP hydrolysis. Hepatic injury elicits intracellular stress that leads to peroxidation of membrane lipids accompanied by alteration of structural and functional characteristics of the membrane, resulting in the altered functions of these enzymes. A similar observation showing disruption in calcium and potassium metabolism possibly due to the damage to transport pumps in the livers of DEN treated rats was reported by Koizumi et al (1995). The reversal in the levels of membrane bound ATPases during treatment with ELE indicates that it is highly effective in maintaining membrane integrity, thereby preventing hepatocellular membrane damage. This observation is further supported by the fact that ELE treatment also decreases the levels of LPO in the liver tissue.

The biochemical findings are supported by histopathological observations of the liver. The histopathological patterns of liver injury observed in rats treated with ethanol and DEN was found to be more pronounced than their individual treatments, indicating

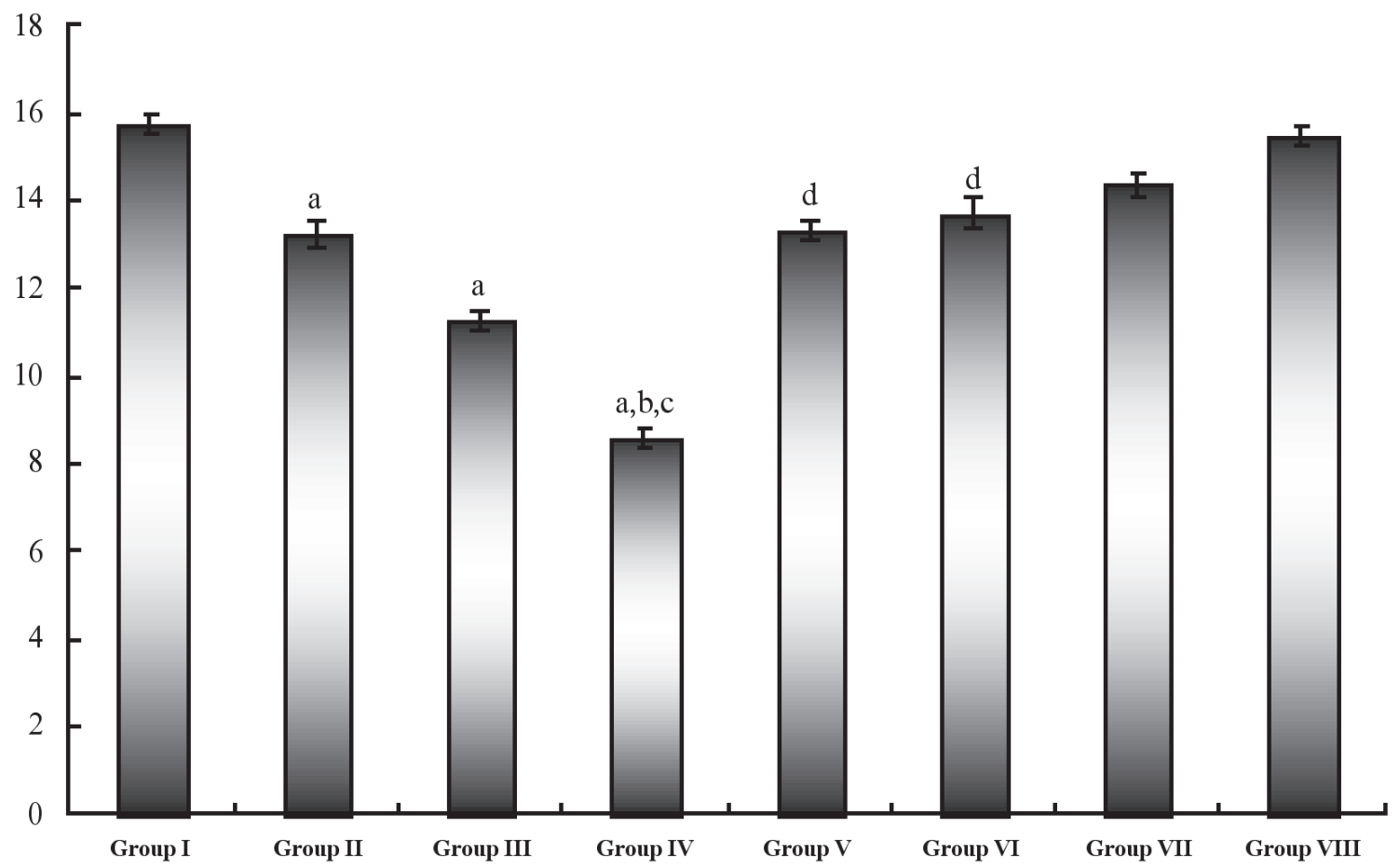

Figure 2: Effect of ELE treatment on the status of vitamin $E$ in the liver tissue of control and experimental animals

Values expressed as mean \pm S.D of 6 animals in each group. Comparisons were made as a compared with Group I; b - compared with Group II; c - compared with Group III; d - compared with Group IV. P $<0.001$ was considered significant. 
augmented hepatocellular damage during combined administration. In contrast to this, liver sections of rats treated with ELE showed improved hepatocellular architecture with signs of recovery, indicating the protective effect of ELE, similar to that of silymarin treatment. Further, individual treatments of ELE and

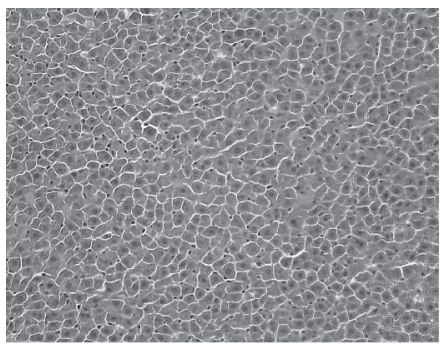

Group I

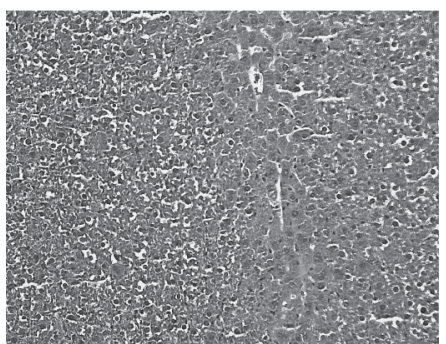

Group III

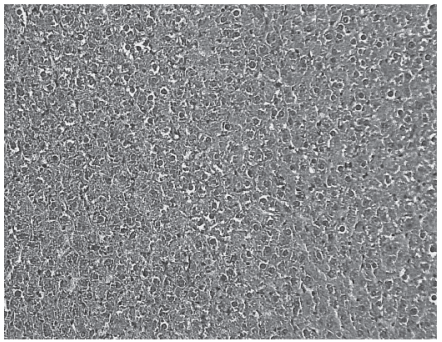

Group V

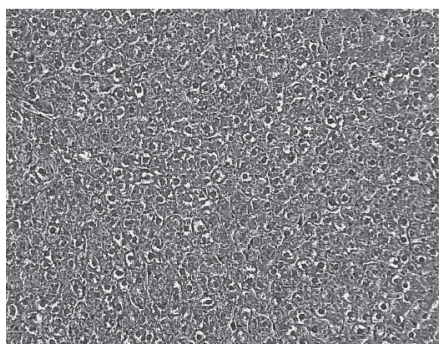

Group VII silymarin alone did not cause any change in the biochemical parameters, as well as pathological observations indicating their non-toxic nature.

It is widely accepted that natural antioxidants strengthen the endogenous antioxidant defenses from ROS ravage and restore the optimal balance by neutralizing

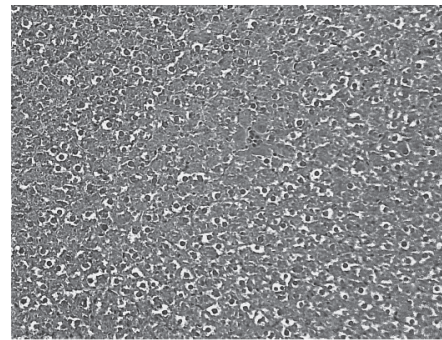

Group II

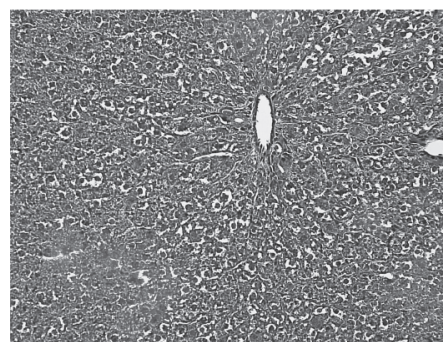

Group IV

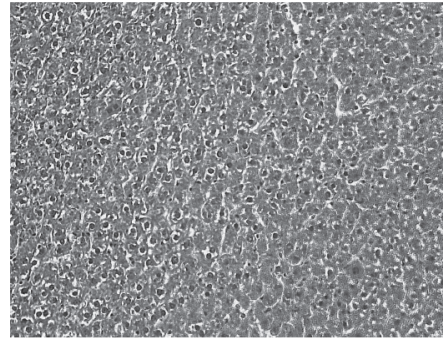

Group VI

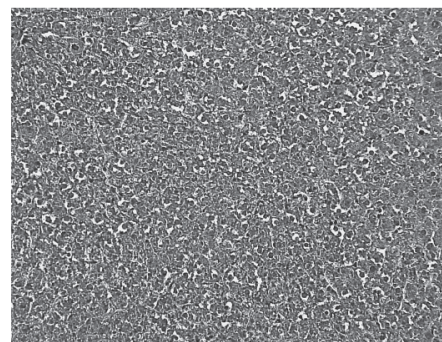

Group VIII

Figure 3: Effect of ELE treatment on the histopathology of the liver tissue of control and experimental animals $(200 \mathrm{X})$ 
free radicals. The results of this study show that the ethanolic leaf extract (ELE) of Cassia fistula exhibits good hepatoprotective effect against DEN induced hepatotoxicity in ethanol pretreated rats. ELE exhibited significant anti-lipid peroxidative, membrane stabilizing, and antioxidant activities, which were comparable with those of the standard hepatoprotective drug silymarin. Silymarin is a well known hepatoprotective agent that it is known to offer hepatoprotection by scavenging free radicals, replenishing intracellular glutathione and inhibiting lipid peroxidation (Fraschini et al., 2002). Since ELE offers identical hepatoprotection to that of silymarin, it can be postulated that ELE might be involved in one or more of the above mentioned mechanism leading to hepatoprotection.

\section{ACKNOWLEDGEMENT}

The authors wish to thank the UGCUWPFE Project (No.HS-43) for the financial assistance provided for this study.

\section{REFERENCES}

BANSAL AK, BANSAL M, SONI G, BHATNAGAR D (2005) Modulation of N-nitrosodiethylamine (NDEA) induced oxidative stress by vitamin $\mathrm{E}$ in rat erythrocytes. Hum Exp Toxicol 24: 297-302.

BAUTISTA A, SPITZER JJ (1999) Role of Kupffer cell in the ethanol-induced oxidative stress in the liver. Front Biosci 4: 589-595.

BERGMEYER HU, SCHEIBE P, WAHLEFELD AW (1978) Optimization of methods for aspartate aminotransferase and alanine aminotransferase. Clin Chem 24: 58-61.

BEUTLER E, DURON O, KELLY BM (1963) Improved method for the determination of blood glutathione. J Lab Clin Med 61: 882-888.

BHAKTA T, MUKHERJEE PK, MUKHERJEE $\mathrm{K}$, BANERJEE S, MANDAL SC, MAITY TK, PAL M, SAHA BP (1999) Evaluation of hepatoprotective activity of Cassia fistula leaf extract. J Ethnopharmacol 66: 277-282.

BONTING SL (1970) Sodium potassium activated adenosine triphosphatase and cation transport. Bitler EE (ed), Vol-1. In: Membrane and ion transport. Interscience Wiley, London, p. 257-263.

BRADFORD MM (1976) A rapid and sensitive method for the quantitation of microgram quantities of protein utilizing the principle of protein-dye binding. Anal Biochem 72: 248-254.

CHATTERJEE A, PAKRASHI SC (1992) The treatise on Indian medicinal plants. Vol-2, CSIR, New Delhi, p. 41.
DIPLOCK AT, RICE-EVANS CA, BURDON RH (1994) Is there a significant role for lipid peroxidation in the causation of malignancy and for antioxidants in cancer prevention? Cancer Res 54: 1952-1956.

FRASCHINI F, DEMARTINI G, ESPOSTI D (2002) Pharmacology of silymarin. Clin Drug Invest 22: 51-65.

GOLDSWORTHY TL, HANIGAN MH, PITOT HC (1986) Models of hepatocarcinogenesis in the rat-contrasts and comparisons. Crit Rev Toxicol 17: 61-89.

GUPTA M, MAZUMDER UK, RATH N, MUKHOPADHYAY DK (2000): Antitumour activity of methanolic extract of Cassia fistula L. seed against Ehrlich ascites carcinoma. J Ethnopharmacol 72: 151156.

HABIG WH, PABST MJ, JAKOBY WB (1974): Glutathione $S$ Transferases. The first enzymatic step in mercapturic acid formation. J Biol Chem 249: 71307139.

HARBORNE JB (1978) Phytochemical methods - A guide to modern techniques of plant analysis. Chapman \& Hall International, London, p. 105.

HJERTEN S, PAN H (1983) Purification and characterization of two forms of a low affinity $\mathrm{Ca}^{2+}$ ATPase from erythrocyte membranes. Biochem Biophys Acta 728: 281-288.

IARC (1972) Monograph on the evaluation of carcinogenic risk of chemicals to man. Vol-1, International Agency for Research on Cancer, Lyon, France.

JAKSZYN P, GONZALEZ CA (2006) Nitrosamine and related food intake and gastric and oesophageal cancer risk: a systematic review of the epidemiological evidence. World J Gastroenterol 21: 4296-303.

KIM BJ, HOOD BL, ARAGON RA, HARDWICK JP CONRADS TP, VEENSTRA TD, SONG BJ (2006) Increased oxidation and degradation of cytosolic proteins in alcohol-exposed mouse liver and hepatoma cells. Proteomics 6: 1250-1260.

KING J (1965a) The phosphohydrolases-acid and alkaline phosphatases. In: Practical Clinical Enzymology. Van Nostrand D Co Ltd, London, p. 191-208.

KING J (1965b) The dehydrogenase (or) oxidoreductase Lactate dehydrogenase. In: Practical Clinical Enzymology. Van Nostrand D Co Ltd, London, p. 8393.

KOIZUMI T, TAJIMA K, EMI N, HARA A, SUZUKI KT (1995) Suppressive effect of molybdenum on hepatotoxicity of $\mathrm{N}$-nitrosodiethylamine in rats. Biol Pharm Bull 18: 460-462.

LU SC (1999) Regulation of hepatic glutathione synthesis: current concepts and controversies. FASEB J 13: 11691183

LUXIMON-RAMMA A, BAHORUN T, SOOBRATTEE MA, ARUOMA OI (2002) Antioxidant activities of phenolic, proanthocyanidins, and flavonoid components in extracts of Cassia fistula. J Agric Food Chem 50: 5042-5047.

MARKLUND S, MARKLUND G (1974) Involvement of the superoxide anion radical in the autooxidation of pyrogallol and a convenient assay for Superoxide dismutase. Eur J Biochem 47: 469-474.

MAZUMDAR UK, GUPTA M, RATH N (1998) CNS activities of Cassia fistula in mice. Phytother Res 12: 520-522.

MITTAL G, BRAR AP, SONI G (2006) Impact of hypercholesterolemia on toxicity of $\mathrm{N}$ nitrosodiethylamine: biochemical and histopathological effects. Pharmacol Rep 58: 413-419.

MIZE CE, LANGDON RG (1962) Hepatic glutathione reductase. I. Purification and general kinetic properties. J Biol Chem 237: 1589-1595. 
OHKAWA H, OHISHI N, YAGI K (1979) Assay for lipid peroxides in animal tissues by thiobarbituric acid reaction. Anal Biochem 95: 351-358.

OHNISHI T, SUZUKI T, SUZUKI Y, OZAWA K (1982) A comparative study of plasma membrane $\mathrm{Mg}^{2+} \mathrm{ATPase}$ activities in normal, regenerating and malignant cells. Biochem Biophys Acta 684: 67-74.

OMAYE ST, TURNBULL JD, SAUBERLICH HE (1979) Selected methods for the determination of ascorbic acid in animal cells, tissues and fluids. Meth Enzymol 62: $1-11$.

RAJESH MG, LATHA MS (2004) Preliminary evaluation of the antihepatotoxic activity of Kamilari, a polyherbal formulation. J Ethnopharmacol 91: 99-104.

ROSALKI SB, RAU D (1972) Serum $\gamma$-glutamyl transpeptidase activity in alcoholism. Clin Chim Acta 39: 41-47.

ROTRUCK JT, POPE AL, GANTHER HE, SWANSON AB, HAFEMAN DG, HOEKSTRA WG (1973) Selenium: Biochemical role as a component of glutathione peroxidase. Science 179: 588-590.

SALLIE R, TREDGER JM, WILLAM R (1991) Drugs and the Liver. Biopharm Drug Dispos 12: 251-259.

SANDER J (1967) Can nitrites in the human diet be the cause of cancerogenesis through formation of nitrosamines? Arch Hyg Bakteriol 151: 22-28.

SAYEED I, PARVEZ S, PANDEY S, BIN-HAFEEZ B, HAQUE R, RAISUDDIN S (2003) Oxidative stress biomarkers of exposure to deltamethrin in freshwater fish, Channa punctatus Bloch. Ecotoxicol Environ Saf 56: 295-301

SCHMITT FC, ESTEVAO D, KOBAYASI S, CURI P, DECAMARGO JL (1993) Altered foci of hepatocytes in rats initiated with diethylnitrosamine after prolonged fasting. Food Chem Toxicol 31: 629-636.

SEHRAWAT A, SULTANA S (2006) Evaluation of possible mechanisms of protective role of Tamarix gallica against DEN initiated and 2-AAF promoted hepatocarcinogenesis in male Wistar rats. Life Science 79: 1456-1465.

SENTHILKUMAR M, SRIPRIYA R, VIJAYARAGHAVAN H, SEHGAL PK (2006) Wound healing potential of
Cassia fistula on infected albino rat model. J Surg Res 131: 283-289.

SEVEN A, GUZEL S, SEYMEN O, CIVELEK S, BOLAYIRLI M, UNCU M, BURCAK G (2004) Effects of vitamin $\mathrm{E}$ supplementation on oxidative stress in streptozotocin induced diabetic rats: investigation of liver and plasma. Yonsei Med J 45: 703-710.

SIDDHURAJU P, MOHAN PS, BECKER K (2002) Studies on the antioxidant activity of Indian Laburnum (Cassia fistula L.): a preliminary assessment of crude extracts from stem bark, leaves, flowers and fruit pulp. J Agric Food Chem 79: 61-67.

SIES H (1985) Oxidative stress: introductory remarks. H. Sies, (Ed.). Oxidative Stress, Academic Press, p. 1-7.

SINGER B, CRUNDERGER D (1984) Molecular Biology, Mutagens and Carcinogens. Plenum Press, New York, p. 127.

SINHA AK (1972) Colorimetric assay of catalase. Anal Biochem 47: 389-394.

SPRON MB, SUH N (2000) Chemoptrevention of cancer. Carcinogenesis 21: 525-530.

SUNILKUMAR KC, MULLER K (1998) Inhibition of leukotriene biosynthesis and lipid peroxidation in biological models by the extract of Cassia fistula. Phytother Res 12: 526-528.

TRICKER AR, PREUSSMANN R (1991) Carcinogenic Nnitrosamines in the diet: occurrence, formation, mechanisms and carcinogenic potential. Mutat Res 259: 277-289.

VARLEY H, GOWENLOCK AH, BELL M (1976) Practical clinical biochemistry Vol-II, $5^{\text {th }}(\mathrm{edn})$ : Hormones, vitamins, drugs and poisons. William Heinemann Medical Books Ltd, London, p. 222-223.

YADAV R, JAIN GC (1999) Antifertility effect of aqueous extract of seeds of Cassia fistula in female rats. Adv Contraception 15: 293-301.

YANG CS, YOO JSH, ISHIZAKI H, HONG J (1990) Cytochrome P45011E1: roles in nitrosamine metabolism and mechanisms of regulation. Drug Metab Rev 22: 147-159.

ZIMMERMAN HJ (1993) Hepatotoxicity. Dis Mon 39: 675-787. 
